\title{
Spinal cord stimulation and the relief of chronic pain
}

\author{
T H KOEZE, $*$ A C de C WILliAMS, $\dagger$ S REIMAN $\dagger$ \\ From the Neurosurgical Unit, ${ }^{*}$ The London Hospital Medical College and the Psychology Department, $\dagger$ The \\ London Hospital, London UK
}

SUMMARY Twenty six patients who had received spinal cord stimulation for chronic pain were evaluated by videotaped structured interviews with staff not directly involved in the patients' care. In addition estimates of pain relief were obtained from clinicians involved in the patients' care and from close relatives and friends. Information about lifestyles and drug usage was also collected and correlated with pain relief. At the time of the interviews half of the patients were receiving $50 \%$ or better relief of their pain.

In 1967 Shealy ${ }^{1}$ reported that electrical stimulation of the dorsal column of the cat spinal cord suppressed the response to noxious stimulation. Two months later Shealy and his colleagues ${ }^{2}$ reported the abolition of pain by electrical stimulation of the dorsal columns of the thoracic spinal cord in a patient with terminal carcinoma. The rationale for this procedure was provided by the "gate theory" of pain proposed by Melzack and Wall. ${ }^{3}$ There was an early, enthusiastic response for this technique. The early reports, however, were often very brief, covered very short periods of treatment and did not always describe the methods of evaluation. Considered and thoughtful evaluations were provided by Nashold ${ }^{45}$ and by Long. ${ }^{6-9}$ The largest number of reports was based upon North American experience. Although the technique has been used in the United Kingdom ${ }^{10}$ and there are reports of success in continental Europe, ${ }^{11-15}$ only Siegfried and Lazorthes ${ }^{16}$ have reported detailed, long term results from Europe.

Many of the patients reported in the North American studies had serious problems with drug abuse and addiction. ${ }^{4917}$ In many reports a considerable number of patients developed their intractable pain after extensive low back surgery. ${ }^{18-22}$ Many patients, especially in the early reports, had serious psychiatric problems. ${ }^{46823-25}$ The organisation of health care in North America meant that some follow-up surveys were based upon postal and/or telephone replies. 469172526

The present survey is based upon 26 patients with

Address for reprint requests: T H Koeze, Neurosurgical Research Laboratory, 56-76 Ashfield St. Whitechapel, London E1 1BB, UK.

Received 30 January 1987 and in revised form 21 April 1987. Accepted 25 April 1987 severe intractable pain who are using spinal cord stimulation for the control of their pain. These patients were regularly seen in a stimulator clinic and were available for extensive interviews and testing. None of these patients had a known psychiatric illness nor were any known to be abusing drugs or involved in legal proceedings for compensation. One patient was excluded from the study because severe language problems made it difficult to obtain reliable responses. Another patient had a stimulator implanted and removed a year before this survey was undertaken and is not included in this study. Otherwise, the group of patients presented in this report includes all the patients who had received a dorsal column stimulator for the relief of pain.

In this report we address the following questions: What amount of pain relief can be expected from spinal cord stimulation in a group of patients who are not abusing drugs, are not involved in litigation, are not overtly psychotic and are regularly seen in a special follow-up clinic? Can the relief of pain be correlated with other factors including change in life-style, drug intake and diagnosis?

\section{Material and Methods}

Patient sample: The survey was based upon 10 female and 16 male patients. The median age was 65 years (interquartile range 50-72). The duration of pain before spinal cord stimulation had an interquartile range of 3-20 years with a median of 7 years. The median period of spinal cord stimulation was 28 months (interquartile range $13 \cdot 5-42 \cdot 5$ ). The details of the patient's diagnosis are shown in table 1 . Two diagnostic categories were used in the analysis: traumatic (phantom limb/stump pain, cauda equina and spinal root and peripheral nerve injuries) consisting of 12 patients; and nontraumatic (post herpetic pain syndrome, claudication, syrinx, cervical spondylosis, arachnoiditis and thalamic syn- 
Table 1 Patient diagnosis

\begin{tabular}{llll}
\hline No & Diagnosis & No & Diagnosis \\
\hline 4 & $\begin{array}{l}\text { Pain associated with } \\
\text { thalamic syndrome }\end{array}$ & 4 & $\begin{array}{l}\text { Amputation with stump pain } \\
\text { Pain with peripheral } \\
\text { vascular disease }\end{array}$ \\
1 & $\begin{array}{l}\text { Syringomyelia } \\
\text { Cervical spondylosis } \\
1\end{array}$ & 1 & $\begin{array}{c}\text { Denervation pain secondary } \\
\text { to pelvic inflammation } \\
\text { Arachnoiditis }\end{array}$ \\
$\begin{array}{l}\text { Post herpetic pain } \\
\text { Root lesions } \\
\text { (trauma or surgery) }\end{array}$ & 1 & $\begin{array}{c}\text { Undiagnosed spinal cord } \\
\text { disease (? myelitis) }\end{array}$ \\
3 & $\begin{array}{c}\text { Peripheral/Cranial Nerve } \\
\text { Lesion(trauma or surgery) } \\
\text { (unknown aetiology) }\end{array}$ & 1 & \begin{tabular}{c} 
Undiagnosed perineal pain \\
\hline
\end{tabular} \\
\hline
\end{tabular}

drome) consisting of 14 patients. Four patients for whom no cause for the pain syndrome could be found were classified in the nontraumatic group.

The majority of patients had utilised other treatments apart from drugs for the relief of their pain before spinal cord stimulation. Three patients had used only noninvasive techniques (ultrasound, diathermy, transcutaneous electrical nerve stimulation (TENS), vibration), and six patients had been treated with invasive but nondestructive techniques (epidural injections, nerve blocks) as well as noninvasive techniques. Fourteen patients had been treated with invasive destructive techniques (nerve or root section, phenol injections, cordotomy, sympathectomy) to control pain in addition to nondestructive measures. Nine patients had been treated unsuccessfully with TENS before receiving dorsal column stimulation.

The patients had extensive experience with analgesic drugs. The history of drug usage was obtained from the patients and by a careful search of medical records. The drugs used were placed into three categories: nonsteroid analgesics, codeine and similar strength drugs and morphine and its derivatives. The "highest" category of drug usage for each patient was recorded. One patient had used nonsteroid analgesics only, 17 had used codeine and/or similar strength analgesics and seven had used morphine or its derivatives for pain relief. There was no known case of drug abuse.

Patients were selected for spinal cord stimulation by a consultant neurosurgeon. Most were referred from neurologists or other neurosurgeons. There was no routine use of psychiatric or psychological screening. There were no patients with known psychiatric disorders.

Spinal cord stimulation Twenty two patients used Medtronic units, two patients used Avery units and two patients used Cordis implanted units. The electrodes were implanted epidurally under general anaesthesia. Pisces electrodes were used in 10 patients, myelostat electrodes were used in 13 patients and three patients were given other types. The amount of spinal cord stimulation varied. Eight patients used continuous stimulation, 11 patients used stimulation for 12 hours each day. Four patients used intermittent stimulation daily and three patients used intermittent stimulation weekly.

Evaluation The patients in this survey were interviewed by either of two psychologists who had not previously met the patient or participated in any way in the patient's treatment. The structured interview used by each psychologist was videotaped. During this interview the patients were given the Melzack pain adjective list ${ }^{27}$ and asked to evaluate their pain relief on a visual analogue scale (VAS).
A relative or close friend was available for a structured interview for 16 patients. The relative also rated the patients' apparent pain relief from spinal cord stimulation on a visual analogue scale.

At the time of these interviews the clinician who regularly saw the patient in the stimulator clinic also rated the patient's apparent pain relief as a percentage estimate. The clinician also asked the patient to rate the "worth" of the treatment on a categorical scale ("very much so", "yes", "not sure", "no" and "absolutely not"). The assessments by the clinician and the psychologist were made independently and only compared after the interview.

\section{Results}

No patient refused to be interviewed or to have the interview videotaped. The patients were willing to answer all questions. One patient expressed serious doubt about the usefulness of the questions, calling the visual analogue scales "hocus pocus"! The reliability of the patients' responses appeared to be high when these could be checked against other sources of information. The patients' estimate of the duration of stimulation and the duration of their pain were both checked against their clinical records. The agreement was good with a kappa value of $0.80+$ for each estimate.

The three dimensional plot of fig. 1 shows the relationship between the patient's estimate of pain relief (VAS), the relative's or close friend's estimate (RVAS) and the clinical estimate (CLINEST). The values, rounded to the nearest whole integer, are on a scale of 0 to 10 where 0 is no pain relief and 10 is $100 \%$ pain relief. Kendall's tau-b, a nonparametric measure of correlation between these variables, was between 0.71 and $0.74(p=0.001)$. The mean of these three variables (MVAS) was used for the estimate of pain relief. Figure 2 is a histogram of the MVAS values. Thirteen of 26 patients had a pain relief estimate of $50 \%$ or more ( 5 or more on the MVAS scale). The distribution shows relatively large numbers of patients at each end of the scale.

There was no correlation (Kendall's tau-b) between MVAS and age or sex. MVAS was positively correlated with pain duration before stimulation $(0.35$, $\mathrm{p}=0.008$ ) and negatively correlated with present pain severity $(-0.31, p=0.019)$ and hours each day in pain $(-0.29, p=0.026)$. The latter two relationships would be expected if the evaluations were consistent. Figure 3 shows a cross tabulation in Chi square form between MVAS and the two diagnostic categories. The results suggest that the "trauma" patients did rather better than the "nontrauma" patients. The probability that this distribution was due to chance was 0.06 (Fischer exact probability).

Many reports (for example ${ }^{49}$ ) report a negative 


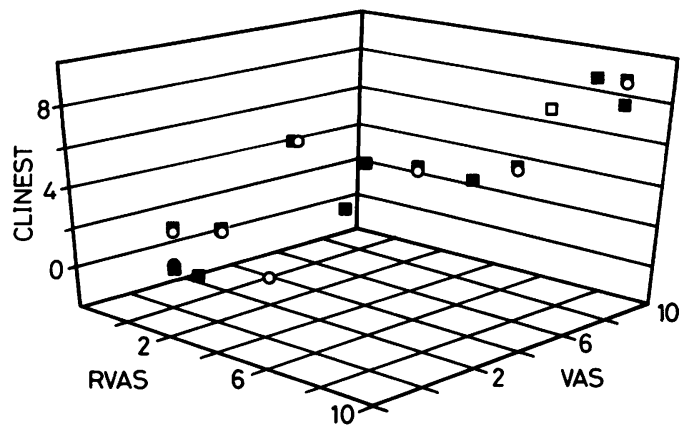

Fig 1 Three dimensional plot of the pain relief estimates made by the patient (VAS), the relative ( $R V A S)$ and the clinician (CLINEST). Perfectly, positively correlated data $(0,0,0 ; 1,1,1 ; 2,2,2$; etc.) would be illustrated by points on a line running from the lower left corner to the upper right.

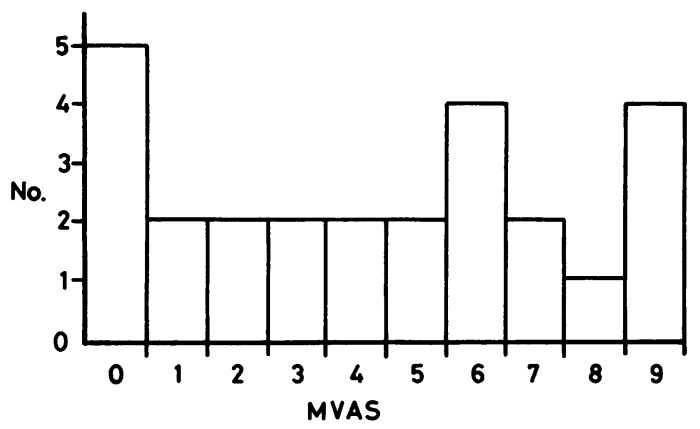

Fig 2 Histogram of the mean estimate of pain relief (MVAS). The pain relief estimate values have been rounded to the nearest whole integer. Zero represents a pain estimate between 0 and less than $10 \%$.

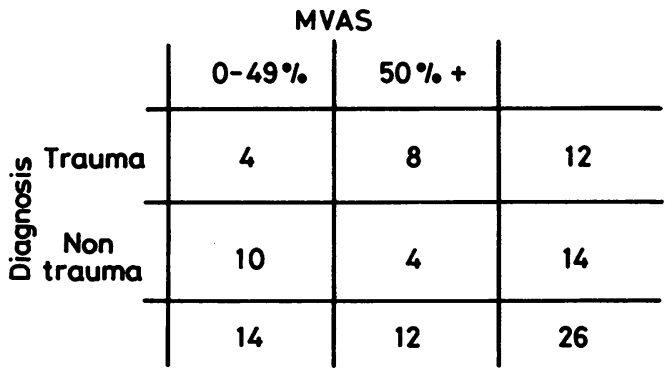

Fig 3 Cross tabulation of diagnostic categories "trauma" and "nontrauma" (see text for further details) with the mean estimate of pain relief (MVAS).

correlation between effectiveness and duration of stimulation. Thus reports of effectiveness of patients who have had stimulation for 1-2 years are often very much better than reports on patients who have been receiving stimulation for $5-10$ years. The interquartile range of stimulation duration was 13.5 to 42.5 months. Surprisingly our results showed a positive nonparametric correlation between MVAS and duration of stimulator use $(0.35, p=0.013)$.

Patients were asked if they had noted any change in their work (W), leisure (L) and domestic (D) activities (Table 2). These were scored as 0 for less, 1 for unchanged and 2 for an increase. These scores were added to produce another variable TOTWLD. There were positive, nonparametric correlations between MVAS and leisure, domestic and TOTWLD scores $(0.35$ to $0.49, p=0.02)$. There was no significant correlation between MVAS and work. Chi square analysis of these variables (recoded to "less or same" and "more") and MVAS (recoded to " $<50 \%$ " and " $50 \%$ or more") revealed that patients with $50 \%$ or more pain relief had increased domestic scores $(p=0.01)$ but not for work or leisure activities. There was a significant negative correlation between age and domestic activity $(-0.29, p=0.04)$ but not between age or sex and any of the other activity variables.

Table 3 records the changes in drug usage. Fifteen patients decreased the use of analgesics while only two increased their usage while using the spinal cord stimulation. The Chi square analysis of the change of analgesic usage with MVAS, however, failed to reach significance although nine patients with $50 \%$ or more pain relief were using less drug than before the stimulation. In all, except for the antidepressants, more patients decreased drug usage than increased. The antidepressant drug usage revealed that six patients were taking more antidepressants than before spinal cord stimulation.

The Melzack pain questionnaire was given to all the patients. The affective category scores, the evaluative category scores and the total word count showed no correlation with MVAS, changes with lifestyle or changes with drug usage.

Many reports of evaluations of spinal cord stimulation have used categories such as "poor", "fair", "good" or "excellent". These classifications are usu-

Table 2 Changes in lifestyle

\begin{tabular}{lllr}
\hline Activity & Less & Same & More \\
\hline Work & $2(8 \%)$ & $22(84 \%)$ & $2(8 \%)$ \\
Leisure & $1(4 \%)$ & $16(61 \%)$ & $9(35 \%)$ \\
Domestic tasks & 0 & $15(58 \%)$ & $11(42 \%)$ \\
TOTWLD & $2(8 \%)$ & $19(73 \%)$ & $5(19 \%)$ \\
\hline
\end{tabular}

Table 3 Changes in drug usage

\begin{tabular}{lllrl}
\hline & None & Less & No change & More \\
\hline Analgesics & 0 & $15(58 \%)$ & $9(35 \%)$ & $2(8 \%)$ \\
Sedatives & 0 & $10(44 \%)$ & $9(39 \%)$ & $4(17 \%)$ \\
Antidepressants & $2(9 \%)$ & $6(26 \%)$ & $9(39 \%)$ & $6(26 \%)$ \\
Benzodiazepines & $4(17 \%)$ & $6(26 \%)$ & $10(44 \%)$ & $3(13 \%)$ \\
Neuroleptics & $9(39 \%)$ & $8(35 \%)$ & $3(13 \%)$ & $3(13 \%)$ \\
\hline
\end{tabular}




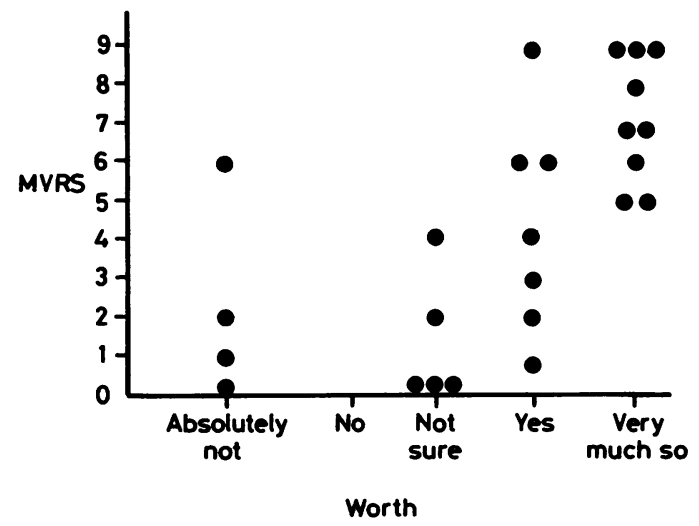

Fig 4 Plot of patient's estimate of "worth" against mean estimate of pain relief ( $M V A S)$.

ally based upon the clinician's evaluation of the patients' responses. Our patients were asked to make a forced choice of five alternatives in response to the question: Do you feel the stimulator is worthwhile? Figure 4 illustrates the response plotted against the MVAS scores. Nine patients with a MVAS score of less than $50 \%$ pain relief responded with a "yes" or "not sure" to the "worth" question.

Considerable technical problems were encountered with the apparatus during the period of this evaluation. Thirty surgical procedures, in addition to the surgery required for the implantation of the stimulating system, were required. Twenty procedures were required to resite the stimulating electrodes after varying periods of successful stimulation. Ten surgical procedures were necessary to repair or replace faulty receivers, fractured "leads" or "leaky" connectors. In addition there were 45 faults to the transmitter/antenna part of the system that required attention. There was one case of wound infection.

\section{Discussion}

There are difficulties in the assessment of pain relief by spinal cord stimulation. ${ }^{69}$ In our study none of the assessments was made by the surgeon involved in the treatment. The psychologists who participated in the assessment had not previously met the patients. The assessing clinician had not been involved in the selection or operative care of the patient but he had participated in the care of the patient over the period of the spinal cord stimulation. The nonparametric correlation between the assessment by the psychologist, the clinician and the patient's relatives was quite high $(0.71$ to 0.74$)$. The mean value of these assessments suggested that at median time of 28 months after implantation half of the patients had a $50 \%$ or better relief of pain.

It is difficult to make a meaningful comparison of our results with other reports because of differences in patient population characteristics and because different methods of assessment were used. Long ${ }^{28}$ reviewed 489 patients from published reports and found "excellent" pain relief in 18\% and "satisfactory" relief in $37 \%$. Erickson and Long" in a 10 year follow up reported a similar figure to ours at 3 years after the implantation of the stimulator. After 10 years only $20 \%$ of the patients reported significant relief. Nashold ${ }^{4}$ reported a success rate of $28 \%$ three years after implantation.

Many investigators have commented on the poor results of long term spinal cord stimulation and this has discouraged many from using the technique for the treatment of intractable pain. However, when it is realised that for most of the patients this technique is a "last resort", then the results are not as disappointing as might first appear. Certainly when they are compared with other techniques such as cordotomy, thalamotomy and nerve section they would appear to be longer lasting and cause less disability. The patients using spinal cord stimulation need less analgesic medication and this may help to avoid addiction and drug abuse.

There was a general reduction in drug intake except for the use of antidepressants. This is because of the belief that antidepressants may act synergistically with spinal cord stimulation, perhaps by activating endogenous antinociceptive systems. ${ }^{29} 30$ The association between antidepressant use, pain relief and activity will be discussed elsewhere. ${ }^{31}$

In our patient population there was a considerable spread in the duration of stimulation and our results may have been biased by the inclusion of a number of patients whose duration of stimulation was less than 2 years. In fact, for this group of patients, the degree of pain relief was positively correlated with the period of stimulator use.

There is often a desire to base an assessment of the utility of spinal cord stimulation on "objective" criteria. Young 22 set his criteria for "success" as the complete or nearly complete relief of pain, cessation of narcotic usage and the return to full activity. $\mathrm{He}$ found the effectiveness of spinal cord stimulation "disturbingly low". However, if these same stringent criteria are applied to other methods of pain control it is unlikely that other methods would do was well as spinal cord stimulation. Erickson and Long ${ }^{9}$ in their 10 year survey compared the unstated "objective" criteria of pain relief with patients' responses in a questionnaire. While $20 \%$ of the patients felt that spinal stimulation was "... of significant value to them for a substantial amount of time", "objectively" only $3 \%$ 
(2 patients) showed significant relief after 10 years.

One suggested "objective" criterion is return to work. ${ }^{31}$ Return to work however, depends upon many factors besides pain relief, particularly in a population with a median age of 65 . As in the study of Nielson et al, ${ }^{25}$ we did not find return to work a significant indicator of pain relief. Increase in other activities involving leisure or domestic life were much better indicators in our population.

We felt that it was important to obtain from the patients their assessment of the "worth" of the technique. This was rather different from an assessment of the pain relief as it would include consideration of the time and trouble involved in returning to the clinic for periodic visits and of the pain and discomfort of repeated surgical procedures to correct technical problems. We were surprised to find nine patients with less than $50 \%$ pain relief responded with a "yes" or "not sure" to the "worth" question. Clearly many patients are prepared to make considerable sacrifice for what others would perhaps regard as marginal pain relief.

At a median time of 28 months, 21 patients felt either "not sure" or were positive in their replies to the "worth" question. Against this must be weighed the "cost" of this achievement. The large number of technical complications have been noted by others. ${ }^{592232}$ In practical terms this means that long term follow-up in clinics prepared to diagnose equipment failures and electrode dislocation are essential to maintain a reasonable success rate. The surgeon must be prepared to operate repeatedly to correct these defects.

There is clearly room for improvement in the available equipment. We have recently been changing from systems with external transmitters to totally implantable devices. This should eliminate many of the problems that occur with the transmitters and antennae. ${ }^{33}$ Better techniques for electrode fixation are urgently required and the problem of fractured "leads" and "leaky" connectors must be solved.

Given the cost of the equipment and the necessary surgery, it would clearly be helpful if procedures which would accurately predict the outcome could be developed. The response to TENS stimulation has been suggested as a screening procedure for spinal cord stimulation. ${ }^{202833}$ Nine of our patients had used TENS stimulation but the response to the stimulation was insufficient to relieve substantially the pain for a significant period. If patients enjoy a reasonable degree of success with TENS it seems sensible to continue this treatment rather than to proceed to spinal cord stimulation. It has been suggested that a successful trial of stimulation with percutaneously implanted electrodes should be used to select patients for permanent spinal cord stimulation. ${ }^{8}$ We have not used this technique because of the risk of infection.

Personality testing (for example the MMPI) has been suggested as an aid in patient selection. ${ }^{173435}$ Others, however, have not found such tests useful in predicting success or failure with spinal cord stimulation. ${ }^{422325}$ Given this uncertainty and the fact that the MMPI has been standardised upon a North American population, we felt its use with our patients would not compensate for the time and effort required of patients and staff. ${ }^{36}$

Daniel $e t a l^{26}$ conducted an interesting study to predict the results of spinal cord stimulation. By using a structured interview and a number of psychological tests, including the MMPI, they were able to predict the outcome successfully in $76.5 \%$ of the patients. An analysis of their spinal cord stimulation data reveals a kappa of 0.44 (se $\pm 0.23, t=1.89,0.10>p>0.05$ ) This is a low value for kappa which suggests that the predictability beyond that which could be assigned to chance is rather low. ${ }^{37}$

The problem of patient selection is even more critical in a state sponsored health care system where the cost of a treatment must compete for scarce funds and methods for selecting patients must be improved. It must be remembered, however, that for many patients spinal cord stimulation is a "last hope". As Sternbach ${ }^{38}$ has suggested it may be unethical to deny a patient access to a therapeutic procedure simply because of a personality profile based upon a psychological test.

\section{References}

1 Shealy CN, Taslitz N, Mortimer JT, Becker DP. Electrical inhibition of pain: Experimental evaluation. Anesth Analg 1967;46:299-305.

2 Shealy CN, Mortimer JT, Reswick JB. Electrical inhibition of pain by stimulation of the dorsal columns. Anesth Analg 1967;46:489-91.

3 Melzack R, Wall P, Pain mechanisms: A new theory. Science 1965;150:971-9.

4 Nashold BS. Dorsal column stimulation for control of pain: A three year follow-up. Surg Neurol 1975;4:146-7.

5 Urban BJ, Nashold BS. Percutaneous epidural stimulation of the spinal cord for relief of pain. Longterm results. $J$ Neurosurg 1978;48:323-8.

6 Long DM, Erickson DE. Stimulation of the posterior columns of the spinal cord for relief of intractable pain. Surg Neurol 1975;4:134-41.

7 Long DM, Hagfors N. Electrical stimulation in the nervous system: The current status of electrical stimulation of the nervous system for the relief of pain. Pain 1975;1:109-23.

8 Long DM, Erickson D, Campbell J, North R. Electrical stimulation of the spinal cord and peripheral nerves for pain control. Appl Neurophysiol 1981;44:207-17.

9 Erickson DL, Long DM. Ten-year follow-up of dorsal column stimulation. Adv Pain Res Therapy 1983;5:583-9.

10 Miles J, Lipton S, Hayward M, Bowsher D, Mumford J, Molony V. Pain relief by implanted electrical stimulators. Lancet 1974;1:777-9. 


\section{Spinal cord stimulation and the relief of chronic pain}

11 Broseta J, Roldan P, Gonzalez-Darder J, Bordes V, BarciaSalorio JL. Chronic epidural dorsal column stimulation in the treatment of causalgia pain. Appl Neurophysiol 1982;45:190-4.

12 Kocher U, Siegfried J, Perret E. Age and personality profiles of patients with chronic pain. Appl Neurophysiol 1982;45:523-7.

13 Krainick J-U, Thoden U, Riechert T. Spinal cord stimulation in post-amputation pain. Surg Neurol 1975;4:167-70.

14 Meglio M, Cioni B, Personal experience with spinal cord stimulation in chronic pain management. Appl Neurophysiol 1981;45:195-200.

15 Waisbrod H, Gerbershagen HV. Spinal cord stimulation in patients with battered root syndrome. Arch Orthop Trauma Surg 1985;104:62-4.

16 Siegfried J, Lazorthes Y. Long term follow-up of dorsal cord stimulation for chronic pain syndrome after multiple lumbar operations. Appl Neurophysiol 1982;45:201-4.

17 Burton C. Dorsal column stimulation: Optimization of application. Surg neurol 1975;4:171-6.

18 Blume H, Richardson R, Rojas C. Epidural nerve stimulation of the lower spinal cord and cauda equina for the relief of intractable pain in failed low back surgery. Appl Neurophysiol 1982;45:456-60.

19 North RB, Fischell TA, Long DM. Chronic dorsal column stimulation via percutaneously inserted epidural electrodes. Appl Neurophysiol 1977;40:184-91.

20 Pineda A. Dorsal column stimulation and its prospects. Surg Neurol 1975;4:157-63.

21 Ray CD, Burton CV, Lifson A. Neurostimulation as used in a large clinical practice. Appl Neurophysiol 1982;45:160-6.

22 Young R. Evaluation of dorsal column stimulation in the treatment of chronic pain. Neurosurgery 1978;3:373-9.

23 Sweet WH, Wepsic JG. Stimulation of the posterior columns of the spinal cord for pain control: Indications, technique and results. Clin Neurosurg 1974;21:278-310.

24 Nashold BS, Friedman H. Dorsal column stimulation for control of pain. J Neurosurg 1972;36:590-7.

25 Nielson KD, Adams JE, Hosobuchi Y. Experience with dorsal column stimulation for relief of chronic intractable pain: 1968-1973. Surg Neurol 1975;4:148-52.

26 Daniel MS, Long C, Hutcherson WL, Hunter S. Psychological factors and outcome of electrode implantation for chronic pain. Neurosurgery 1985;17:773-7.

27 Melzack R, Torgerson WS. On the language of pain. Anesthesiology 1971;34:50-9.

28 Long DM. Use of peripheral and spinal cord stimulation in the relief of chronic pain. Adv Pain Res Ther 1976;1:395-403.

29 France RD, Houpt JL, Ellinwood EH. Therapeutic effects of antidepressants in chronic pain. Gen Hosp Psychiatry 1984;6:55-63.

30 Clifford DB. Treatment of pain with antidepressants. Am Fam Physician 1985;31:181-5.

31 Sweet WH, Wepsic JG. Stimulation of the posterior columns of the spinal cord for pain control. Surg Neurol 1975;4:133.

32 Koeze TH, Simpson BA, Watkins ES. Diagnosis and repair of malfunctions of implanted central nervous system stimulators. Appl Neurophysiol 1984;47:111-6.

33 Shealy CN. Six years experience with electrical stimulation for control of pain. Adv Neurol 1974;4:775-82.

34 Shealy CN. Pain suppression through posterior column stipulation (sic). In: Fields WS, ed. Neural Organization and its Relevance to Prothesis. International Medical Book Corp. New York 1973.

35 Taylor WP, Stern WR, Kubiszyn TW. Predicting patients' perceptions of response to treatment for low-back pain. Spine 1984;9:313-6.

36 Main CJ. Must we play the MMPI game? Readings in Psychology and Pain. Proceedings of 1st Int. Conf. of Pain Interest Groups. Broome AK, ed. Birmingham. Dudley Psychology Services 1985:186-201.

37 Fleiss JL. Statistical Methods for Ratios and Proportions. 2 ed. New York: John Wiley \& Sons 1981.

38 Sternbach RA. Psychological aspects of pain and the selection of patients. Clin Neurosurg 1974;21:323-33. 